\title{
EDITORIAL
}

El presente año, tendremos la oportunidad de escuchar a los colegas psicólogos procedentes de otros países así como a nuestros compatriotas, exponiendo sus diferentes trabajos de investigación en dos congresos: el primero el XXIX Congreso Interamericano, organizado por la Sociedad Interamericana filial Perú, a realizarse en la segunda quincena del mes de Julio; el segundo, el XI Congreso Nacional y I Internacional, organizado por el Colegio de Psicólogos del Perú, a realizarse en la segunda quincena del mes de setiembre.

Estos certámenes debemos entenderlos como tribunas abiertas al intercambio de conocimientos, a la consolidación de ideas hacia proyectos transculturales, asimismo, deberán ser escenarios de franca y sincera comunicación, con el propósito de establecer redes de coordinación e intercambio de manera permanente, más allá de las formalidades académicas.

En el presente año, denominado «Año de los derechos de la persona con discapacidad y el centenario del nacimiento de Jorge Basadre Grohmann», debemos en nuestra calidad de profesionales dedicados a la investigación, diagnóstico y recuperación de las personas que por causas diferentes sufren de alguna discapacidad, llamar a la reflexión de los diferentes agentes activos de nuestra comunidad, a fin de comprender el estado especial en que se encuentran algunos hermanos y que requieren de parte de quienes se ubican en la otra orilla, su contribución desde su actividad diaria para no hacerles más difícil su existencia. Por ejemplo, las municipalidades deben priorizar la modificación de pistas y veredas para la fácil circulación de quienes usan sillas de ruedas, el ciudadano debe ser sensible para atender a un invidente cuando este lo requiera, los transportes públicos deben ponerse en la situación del que ahora sufre pensando que muy bien pudieron ser ellos quienes podrían encontrarse en tal situación y que obviamente 10 menos que desearían es encontrar a un transportista que los reciba con paciencia y una sonrisa amable.

Por ello saludamos a los profesionales técnicos y otras personas que trabajan directamente con discapacitados, en especial a nuestra colega Doctora Ernestina López Vega quien con paciencia y amor ejerce su profesión en la unidad de rehabilitación de la clínica San Juan de Dios, quien por su propia decisión no continuará trasmitiendo su experiencia en nuestras aulas sanmarquinas por haber pasado al cese.

Desde estas páginas queremos sugerir que la nominación de los años venideros se anuncie con seis mese de anticipación, a fin de que las diferentes instituciones dedicadas a la investigación y a la formación de profesionales puedan desarrollar políticas en la dirección que dicha nominación del año sea efectiva y no simplemente un nombre para un año más.

Esta misma actitud hacia la nominación del año está ocurriendo con nuestro ilustre historiador «el maestro» Jorge Basadre, porque al margen de ceremonias protocolares por su onomástico o por su fallecimiento o alguna otra ocasión, las acciones llevadas a 
cabo, distan mucho de poner énfasis en la profundidad de su pensamiento y en sus aportes a la comprensión y la solución de los grandes problemas, de este país al que gozó y sufrió, y para el cual vivió. Por ejemplo, no hemos analizado el «sultanismo», como un estilo de gobierno que asume aquel que llega al poder, aun cuando este haya sido alcanzado por elección y tampoco estamos extrayendo las lecciones más importantes de los episodios cruciales de nuestra trayectoria republicana y de la interpretación de lo que jamás debió ocurrir, la denominada Guerra del Pacifico, desarrollada por intereses mezquinos, no de los pueblos participantes, sino de actores ocultos con alto poder de decisión.

Cuanto beneficio podríamos sacar de la nominación de un año si tenemos la voluntad auténtica que esta sirva de justificación para remembrar, dando vida a lo que creemos por convicción que debe mantenerse como lecciones permanentes, orientadas a evitar que el mismo error se cometa.

Con la convicción de que la investigación es una de las actividades que Don Jorge Basadre Grohman quiso impulsar a través de su labor en la Biblioteca de la Universidad, permitiendo el acceso a las publicaciones que usan los investigadores, se publica este ejemplar de nuestra revista, rindiendo homenaje a tan egregio maestro.

\section{EL DIRECTOR}

